Tropical Journal of Pharmaceutical Research March 2020; 19 (3): 489-495

ISSN: $1596-5996$ (print); 1596-9827 (electronic)

(C) Pharmacotherapy Group, Faculty of Pharmacy, University of Benin, Benin City, 300001 Nigeria.

Available online at http://www.tjpr.org

Original Research Article

http://dx.doi.org/10.4314/tjpr.v19i3.5

\title{
MiR-138 ameliorates myocardial ischemia/reperfusion injury by targeting intercellular cell adhesion molecule 1
}

\author{
Zhanling Liao ${ }^{1}$, Xiaoli Cheng ${ }^{2}$, Chunyan Xiang ${ }^{3}$, Feng Liu'* \\ ${ }^{1}$ Department of Cardiology , Suzhou Kowloon Hospital, Shanghai Jiaotong University School of Medicine, Suzhou City, \\ Jiangsu Province 215028, ${ }^{2}$ Department of Cardiology, Shengjing Hospital Affiliated to China Medical University, Shenyang City, \\ Liaoning Province 110004, ${ }^{3}$ Department of Cardiology, Dongying People's Hospital, Dongying City, Shandong Province \\ 257000, China \\ *For correspondence: Email: FengLiudfr@163.com; Tel: +86-512-62629305
}

Sent for review: 12 December 2019

Revised accepted: 26 February 2020

\begin{abstract}
Purpose: To explore the effect of miR-138 on regulating intercellular cell adhesion molecule 1 (ICAM-1) expression in endothelial cells to alleviate cardiac ischemia/reperfusion (I/R) injury and its related mechanisms.

Methods: The left anterior descending artery of the heart was occluded for 30 min and then perfused for $2 \mathrm{~h}$ to induce a rat model of cardiac I/R injury. H9C2 cells were cultured in an anoxic medium without serum to establish the model of hypoxia/reoxygenation (H/R). Triphenyl tetrazolium chloride (TTC) staining was applied to measure myocardial infarction sizes in rat hearts. The mRNA expression levels of miR-138 and ICAM-1 were evaluated by quantitative real-time polymerase chain reaction (qRT-PCR). Dual luciferase reporter assay was used to identify the target of miR-138. The agomiR-138 and miR-138 mimics were transfected into H9C2 cells; exogenous ICAM-1 was also administered, and ROS accumulation, cell viability, and apoptosis were measured. Furthermore, the underlying mechanism was investigated.

Results: MiR-138 was downregulated both in vitro and in vivo. AgomiR-138 reduced myocardial infarction area, decreased ROS production and suppressed cell apoptosis in a rat model of cardiac $I / R$ injury. On the other hand, miR-138 mimics increased cell viability, enhanced ROS production and induced cell apoptosis in H/R-induced H9C2 cells. Further analysis verified ICAM-1 as a target of miR138. Besides, exogenous ICAM-1 inhibited the protective effect of miR-138 on H/R-induced apoptosis in vitro.

Conclusion: MiR-138 may protect against injury of myocardial I/R by targeting ICAM-1. The results also provide insight into miR-138/ICAM-1 axis as new therapeutic targets for myocardial I/R injury.
\end{abstract}

Keywords: Intercellular cell adhesion molecule 1, MicroRNA-138, Myocardial/ischemia reperfusion injury, Reactive oxygen species

This is an Open Access article that uses a fund-ing model which does not charge readers or their institutions for access and distributed under the terms of the Creative Commons Attribution License (http://creativecommons.org/licenses/by/4.0) and the Budapest Open Access Initiative (http://www.budapestopenaccessinitiative.org/read), which permit unrestricted use, distribution, and reproduction in any medium, provided the original work is properly credited.

Tropical Journal of Pharmaceutical Research is indexed by Science Citation Index (SciSearch), Scopus, International Pharmaceutical Abstract, Chemical Abstracts, Embase, Index Copernicus, EBSCO, African Index Medicus, JournalSeek, Journal Citation Reports/Science Edition, Directory of Open Access Journals (DOAJ), African Journal Online, Bioline International, Open-J-Gate and Pharmacy Abstracts

\section{INTRODUCTION}

Ischemic heart diseases (IHD) can promote the development of blood vessel diseases and ultimately result in death[1]. To date, reperfusion of arterial blockages is main treatment method for IHD. However, cardiac ischemia/reperfusion $(\mathrm{I} / \mathrm{R})$ injuries were induced by reperfusion(myocardial infarction, myocardial cell death, and microvascular obstruction etc.) [2]. 
Thus, the underlying mechanisms of cardiac I/Rinduced injury were needed to be further explored.

MicroRNAs, composed of $18-20$ nucleotides, are endogenous, single-stranded RNAs that regulate the expression of gene through targeting the 3'-terminal untranslated region (UTR) of mRNA at the posttranscriptional level [3]. MicroRNAs have been shown to regulate more than $60 \%$ of human genes [4]. Numerous studies have shown that microRNAs regulate many critical pathological and physiological processes $[5,6]$, including cell migration, proliferation, and apoptosis. It has been proved that miR-21, miR-141, and miR-320 act as key regulators of cardiac development and myocardial injury [7]. In particular, miR-138 exhibited protective effects on cerebral $I / R$ injuries in rats [8], while the effect of miR-138 on cardiac I/R injury remains unclear.

MiR-138 was previously found to regulate the growth of pancreatic cancer by targeting FOXC1 [9]. According to a microrna.org prediction, miR138 may target Intercellular Cell Adhesion Molecule-1 (ICAM-1), a downstream factor regulated by nuclear factor-kappa B (NF-kB). In fibroblasts, macrophages, lymphocytes, and vascular endothelial cells, ICAM-1 was highly expressed [10] and is considered as an important pro-inflammatory factor that mediates the inflammatory response to reperfusion injury [11]. Under normal physiological state, endothelial cells express relatively low levels of ICAM-1, its expression level can be increased upon stimulation of various inflammatory factors, hypertension, and $\mathrm{I} / \mathrm{R}$. Extensive studies have shown that reduced ICAM-1 expression acts critical effects on cardiac I/R injuries [11].

This study aimed to clarify the roles of miR-138 in the regulation of ICAM-1activityin endothelial cells during cardiac $I / R$ injury and reveal the underlying mechanisms. Elevated miR-138 levels attenuated myocardial infarction, accumulation of reactive oxygen species (ROS), cell viability, and cell apoptosis by targeting ICAM-1in vivo and in vitro, suggesting that miR-138 might ameliorate the damage of cardiac $I / R$ injury through targeting ICAM-1.

\section{EXPERIMENTAL}

\section{Establishment of a cardiac $I / R$ injury rat model}

The Animal Experiment Center of Suzhou Kowloon Hospital provided fifty adults SpragueDawley (SD) rats (male, 260-350 g). Rats were housed in standard conditions and provided feed and water weekly. Experiments were followed the guidelines of Animal Use of the National Institutes of Health's Code of Ethics [12] and was approved by the institutional Ethics Committee (Approval no. 2017SME0215). SD rats were randomly grouped(a) Sham group, (b) I/R group, (C) $\mathrm{I} / \mathrm{R}+$ agomiR-NC group, and (D) $\mathrm{l} / \mathrm{R}+$ agomiR-138 group ( $n=10$ per group). Except the sham group, rats were housed in standard conditions for 3 days prior to surgical injury by myocardial I/R. Surgical injury was performed as previously reported [13]. Thirty minutes after ischemia, the slip was released, and reperfused the myocardium for $2 \mathrm{~h}$. Finally, collected the blood samples of the sacrificed rats for biochemical analysis, and the peri-infarct zones of the hearts were used for morphological and biochemical tests. The model rats were injected through the tail vein with a agomiR-138 or a scrambled miRNA analog (RiboBio. Co., GuangZhou, China), twice a week, the dose in $20 \mathrm{~mL}$ of saline is $20 \mathrm{mg} / \mathrm{kg} /$ day.

\section{Establishment of an ischemic cell model and associated treatment}

Rat cardiomyocytes $\mathrm{H} 9 \mathrm{C} 2$ cells were provided by the ATCC (CRL-1446, USA) and cultured in DMEM (Thermo Fisher Scientific, USA) with $1 \%$ penicillin/streptomycin and 10\%FBS (SigmaAldrich, USA). The medium was replaced with serum-free DMEM when the cell confluence reached approximately $80-85 \%$ to establish an ischemic cell model. Then, cells were cultured for $24 \mathrm{~h}$ (humidified, $5 \% \mathrm{CO}_{2}$ and $1 \% \mathrm{O}_{2}$ ). Transfection of oligonucleotides NC-mimic, miR138 mimic, agomiR-138, agomiR-NC, or miR-138 mimic + $50 \mathrm{nM}$ ICAM-1 intoH9C2 cells through Lipofectamine 2000 (Invitrogen, Carlsbad, CA, USA).

\section{Measurement of myocardial infarct size}

Rat hearts were stored at $-18{ }^{\circ} \mathrm{C}$ for $15 \mathrm{~min}$, and then five uniform tissue sections were cut parallel to the line below the heart ligature and the coronary sulcus. All sections were weighed and cultured for $15 \mathrm{~min}$ in triphenyl tetrazolium chloride (TTC) in the dark at $37{ }^{\circ} \mathrm{C}$ for pathological examination. Image-Pro Plus software (Version 4.2, Media Cybernetics, LP, USA) was used to analyze white or pale nonTTC-stained areas and red TTC-stained areas. Finally, the ratio of infarcted myocardium to the entire myocardial tissue section $(R)$ was obtained as in Eq 1.

$\mathrm{R}=\mathrm{S} / \mathrm{A} \ldots \ldots \ldots \ldots(1)$

Trop J Pharm Res, March 2020; 19(3): 490 
where $S$ and $A$ are the infarct size and total heart area, respectively.

\section{Quantitative RT-PCR analysis}

The tissues and cell samples RNAs were extracted by MagBeads Total RNA Extraction Kit (TIANGEN, Beijing, China). Target gene specific primers were shown in Table 1. TB green qPCR master mix (TAKARA BIO INC, Tokyo, Japan) was used for fluorescence quantitative detection according to the manufacturer's instructions. The fluorescence values were expressed by $2^{-\Delta \Delta C t}$ and quantified [14].

Table 1: Primer sequences

\begin{tabular}{lll}
\hline Genes & Forward (5'- 3') & Reverse (5'-3') \\
\hline miR-138 & AGCUGGUGUUGU & GTGCAGGGTCC \\
& GAAUC & GAGGT \\
ICAM-1 & GATGCTGACCCT & AGCACTTGCGGT \\
& GGAGAGCA & CCACGATG \\
U6 & GTAGTCGGCGAA & ACCGTGGATGCA \\
& GGTCTCAC & ATGCCTAA \\
GAPDH & AAGGAAATGAATG & TAGGAAAAGCAT \\
& GGCAGCC & CACCCGGA \\
\hline
\end{tabular}

Determination of creatine kinase (CK) and serum lactate dehydrogenase (LDH) activities

Centrifuged the blood samples for $15 \mathrm{~min}$ at $4,500 \times g$, and serum samples were kept at $80^{\circ} \mathrm{C}$. LDH and CK levels were evaluated by a commercial ELISA kit (Thermo Fisher Scientific, USA).

\section{Assessment of ROS levels}

Homogenized cells in lysis buffer and at $4^{\circ} \mathrm{C}$, centrifuged for $15 \mathrm{~min}$ at $12,000 \times \mathrm{g}$, discarded the cell pellets. 2,7-dchlorofluorescein diacetate (DCFH-DA) was used to assess ROS levels by using a ROS assay kit (Abeam, UK).

\section{MTT analysis}

Hypoxia/reoxygenation (H/R) and/or NCmimic/miR-138 mimic-treated $\mathrm{H} 9 \mathrm{C} 2$ cells were seeded at 96 -well microplates $\left(4 \times 10^{4}\right.$ cells per well). $0.5 \mathrm{mg} / \mathrm{mL}$ of 3-[4,5-dimethylthiazol-2-yl]2,5 diphenyl tetrazolium bromide solution (Thermo Fisher Scientific, USA) was then added after seeding for $24 \mathrm{~h}$, and the cultures were incubated for $4 \mathrm{~h}$ at $37^{\circ} \mathrm{C}$ and measured at $\lambda=450 \mathrm{~nm}$.

\section{Apoptosis analysis}

Apoptotic cells were formalin-fixed on a 5-mm thick heart tissue section, deparaffined, and treated with proteinase $\mathrm{K}(10-20 \mathrm{mg} / \mathrm{mL})$ were labeled with TUNEL for $15 \mathrm{~min}$ at $25^{\circ} \mathrm{C}$. After TUNEL labeling, $0.344-\mathrm{mm}^{2}$ sections were viewed at 400x magnification using a light microscope (Olympus, Tokyo, Japan) to quantify apoptotic cells, which were identified as dark green.

In addition, resuspended the cells in Annexin binding buffer $(200 \mu \mathrm{L})$ with annexin V-FITC (10 $\mu \mathrm{L})$ and $\mathrm{PI}(5 \mu \mathrm{L})$ and were cultured in the dark for $10 \mathrm{~min}$ at $25^{\circ} \mathrm{C}$. Flow cytometry (Abcam, USA) was used to analyze the double-stained cells.

\section{Luciferase activity}

The wild-type (WT) and mutant (MUT)ICAM-1 3'UTR binding with putative miR-138 site were synthesized and inserted into the pmirGLO dual luciferase reporter vector (YouBio, Changsha, China). Transfection of the WT or MUT-ICAM-1 3'-UTR reporter vectors and NC-mimic/miR-138 mimic in HEK293T cells (45\% confluence). The luciferase activity was evaluated by a dual luciferase assay system (Promega, Madison, USA) after $48 \mathrm{~h}[15]$.

\section{Western blot analysis}

First, homogenized tissues on ice for 30 min with RIPA buffer (Sigma-Aldrich, USA) and protease inhibitor. Next, centrifuged the tissue homogenates for $15 \mathrm{~min}$ at $12,000 \mathrm{~g}$, and collected the supernatants and stored at $-20^{\circ} \mathrm{C}$. Separated the proteins in the supernatants by $12 \%$ SDS-polyacrylamide gels (PAGE) and transferred onto membranes of PVDF. Nonspecific binding was blocked by Tris-buffered saline (TBS) with 3\% BSA (TBS and $0.1 \%$ Tween 20) under gentle shaking at $25^{\circ} \mathrm{C}$ for $1 \mathrm{~h}$.

Simultaneously incubated the membranes with the primary antibodies: anti-cleaved caspase-3 and 9 (1:1,000, Applygen, Beijing, China), antiBcl-2 and Bax (1:500, Applygen), anti-ICAM-1 (1:500, Abcam, USA), and anti-GAPDH (1:1000,Abcam) at $4^{\circ} \mathrm{C}$ overnight. Proteins were visualized by a LAS-4000 mini system (Fujifilm, Japan). Protein intensity was quantified using Quantity One software.

\section{Statistical analysis}

Data was analysed by GraphPad 8.0 and presented as mean \pm standard deviation (SD). Variance (ANOVA) was used to analyze differences among the different groups and $p<$ 0.05 was regarded as significant.

Trop J Pharm Res, March 2020; 19(3): 491 


\section{RESULTS}

Effects of agomiR-138 on myocardial infarction area, ROS production and cell apoptosis

The I/R group showed an obvious increase $(p<$ 0.001 ) in myocardial infarction area as compare to that in the sham group. However, I/R + agomiR-138 group exhibited a significant decrease in myocardial infarction area, compared to that in $\mathrm{I} / \mathrm{R}+$ agomiR-NC group (Figure $1 \mathrm{~A}, p<0.001$ ). Downregulation of miR138 was observed in $\mathrm{l} / \mathrm{R}$ group compared to sham group. Moreover, miR-138 level was markedly increased in the IR + agomiR-138 group as compared to that in $\mathrm{l} / \mathrm{R}+$ agomiR-NC group ( $p<0.001$; Figure $1 \mathrm{~B}$ ). The serum LDH and CK activities were significantly elevated during $\mathrm{I} / \mathrm{R}$ injury $(p<0.001$, Figure $1 \mathrm{C})$. However, agomiR-138 treatment reduced the activities of $\operatorname{LDH}(p<0.01)$ and CK $(p<0.001)$ after I/R as compare to that of the I/R + agomiR$\mathrm{NC}$ group. ROS was accumulated in I/R rats as compared to that of the sham group (Figure $1 \mathrm{D}$ ). In the I/R + agomiR-138 group, ROS production was markedly decreased as compare to that of the I/R + agomiR-NC group. In addition, TUNEL assay showed that the apoptotic cell number was markedly higher in the I/R group compared to that in sham group, whereas agomiR-138 suppressed cell apoptosis upon I/R treatment (Figure $1 \mathrm{E}$ ).

Effects of niR-138 mimics on cell viability, ROS production and cell apoptosis on H/Rinduced $\mathrm{H} 9 \mathrm{C} 2$ cells

MiR-138 was significantly downregulated in $H / R$ cells $(p<0.001)$, whereas miR-138 were upregulated in the $\mathrm{H} / \mathrm{R}+\mathrm{miR}-138$ mimic group $(p$ $<0.001$ ) as compare to that in the H/R + NCmimic group (Figure $2 \mathrm{~A}$ ). MTT analysis showed that, as compare to the control group, the cell viability was markedly decreased in the $H / R$ group $(p<0.01)$. The higher cell viability was found in the miR-138 mimic+ H/R group than NC-mimic + H/R group (Figure $2 \mathrm{~B}, p<0.01$ ). Serum LDH and CK activities were obviously improved in H/R-induced H9C2 cells $(p<0.01)$, while miR-138 mimic reduced $\mathrm{LDH}$ and $\mathrm{CK}$ activities under $\mathrm{H} / \mathrm{R}$ treatment as compare to that of the $\mathrm{H} / \mathrm{R}+\mathrm{NC}$-mimic group (Figure $2 \mathrm{C}, \mathrm{p}<$ $0.05 ;$ ). ROS levels in H9C2 cells were markedly enhanced in the $H / R$ group, whereas miR-138 mimics under $\mathrm{H} / \mathrm{R}$ condition led to markedly decreased ROS production (Figure 2 D). Besides, H/R treatment significantly induced cell apoptosis as shown by flow cytometry ( $p<$ 0.001). However, miR-138 mimics markedly inhibited H/R-induced cell apoptosis (Figure $2 \mathrm{E}$, $p<0.01)$. In addition, reduced Bcl-2 expression and elevated expression levels of cleaved caspase-9, Bax and cleaved caspase-3 (all $p<$ 0.001 ) were found in $\mathrm{H} 9 \mathrm{C} 2$ cells induced by $\mathrm{H} / \mathrm{R}$ .However, these effects $(p<0.001)$ were ameliorated by miR-138 mimics as compared to the NC-mimic + H/R group (Figure $2 \mathrm{~F}$ ).



Figure 1: Effect of agomiR-138 on a rat model of cardiac I/R injury. (A) TTC staining of myocardial infarct size in rats. (B) miR-138 mRNA expression was assessed by qRT-PCR. (C) Serum levels of LDH and CK were determined using ELISA. (D) Accumulation of ROS was determined with fluorometric analysis. (E) Apoptosis rates of cells were assessed with a TUNEL assay; ${ }^{* * *} p<0.001$ vs. sham group, ${ }^{\# \#} p<0.01$, ${ }^{\# \# \# p<}$ 0.001 vs. I/R + agomiR-NC group

\section{ICAM-1 was targeted by miR-138}

Microrna.org predicted that ICAM-1) was a putative target of miR-138. The MUT and WT 3'UTRs of ICAM-1 containing the miR-138 binding site were cloned into the reporter system (Figure 3 A). The luciferase activity was inhibited after co- transfection of miR-138 mimic and 3'-UTR of WT-ICAM-1 (Figure 3 A, $p<0.001$ ), while had no significant effects on that of MUT-ICAM-1 3'UTR. Moreover, the ICAM-1 mRNA and protein expressions in $H / R$ cells were significantly reduced by miR-138 mimic $(p<0.001$ and $p<$ 0.01), whereas ICAM-1 mRNA and protein expressions $(p<0.01)$ were significantly improved in miR-138 inhibitor $+H / R$ group (Figure $3 \mathrm{~B}$ and $\mathrm{C}$ ). Moreover, ICAM-1 protein 
expression was increased in $\mathrm{I} / \mathrm{R}$ rats as compared to sham group $(p<0.001)$, but was decreased by agomiR-138 as compared to I/R + agomiR-NC group (Figure $3 \mathrm{D}, p<0.01$ ).

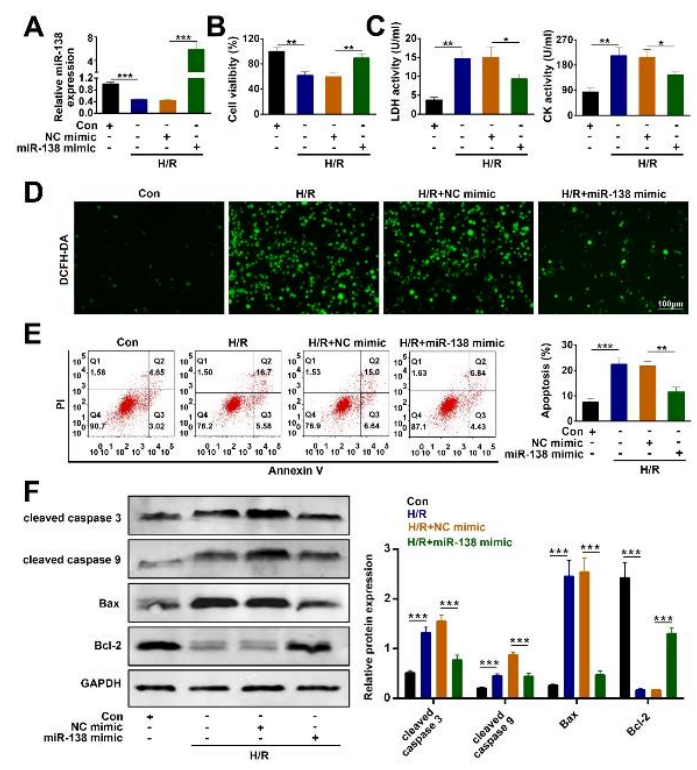

Figure 2: Effects of niR-138 mimics on cell viability, ROS production and cell apoptosis on H/R-induced $\mathrm{H} 9 \mathrm{C} 2$ cells. (A) The expression of miR-138 was assessed by qRT-PCR. (B) The cell viability was determined by MTT assay. (C) The LDH and CK levels of $\mathrm{H} 9 \mathrm{C} 2$ cells were assessed by ELISA. (D) The accumulation of ROS in $\mathrm{H} 9 \mathrm{C} 2$ cells was determined by fluorometric analysis. (E) Cell apoptosis was examined by annexin V-FITC/PI double staining. (F) Apoptosis-associated proteins were examined by Western blotting; ${ }^{* *} p<0.01,{ }^{* *} p<0.001$ vs. control

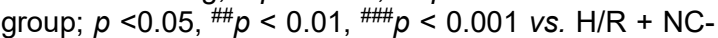
mimic group

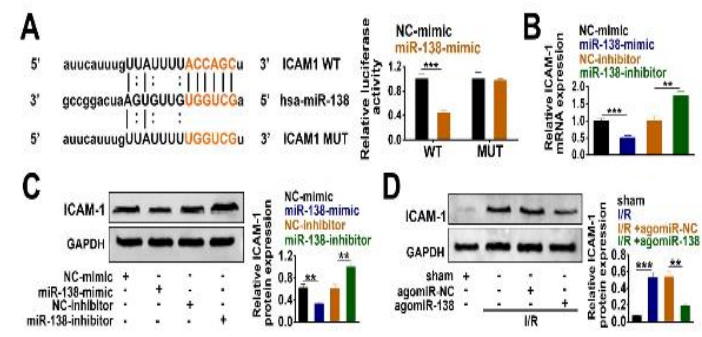

Figure 3: MiR-138 targeted ICAM-1. (A) The miR-138 binding site on the $3^{\prime}-\mathrm{UTR}$ of ICAM-1 mRNA was predicted, and luciferase activity was determined in $\mathrm{H} / \mathrm{R}$ cells. (B) ICAM- 1 mRNA levels in H/R cells were detected by qRT-PCR. (C) Protein levels of ICAM-1 in $\mathrm{H} / \mathrm{R}$-induced $\mathrm{H} 9 \mathrm{C} 2$ cells were analyzed by Western blotting. (D) Protein levels of $I C A M-1$ in the rat cardiac I/R injury model; ${ }^{* *} p<0.01,{ }^{* * *} p<0.001$ vs. NCmimic group, ${ }^{\#} p<0.05$ vs. $\mathrm{H} / \mathrm{R}+\mathrm{NC}$-inhibitor group, $\%$ $\% \% p<0.001$ vs. I/R group, ${ }^{\&} p<0.01$ vs. I/R + agomiR-NC group
Exogenous ICAM-1 suppressed the protection of miR-138 in $\mathrm{H} 9 \mathrm{C} 2$ cells induced by $H / R$

To investigate whether exogenous ICAM-1 affected cell viability in $\mathrm{H} 9 \mathrm{C} 2$ cells induced by $H / R$, MTT analysis exhibited that the cell viability was markedly reduced in themiR-138 mimic + ICAM-1+ H/R group, compared to miR-138 mimic $+H / R$ group (Figure $4 A, p<0.05$ ). In addition, serum levels of $\mathrm{LDH}$ and $\mathrm{CK}$ were significantly upregulated $(p<0.05, p<0.01)$ with miR-138 mimic + ICAM-1 treatment upon $\mathrm{H} / \mathrm{R}$ conditions, compared to miR-138 mimic $+H / R$ group (Figure $4 \mathrm{~B}$ ). In addition, the ROS levels were markedly improved in the miR-138 mimic + ICAM-1+ H/R group as compared to the miR-138 mimic $+\mathrm{H} / \mathrm{R}$ group (Figure $4 \mathrm{C}$ ). In addition, miR138 mimic + ICAM-1 treatment significantly triggered cell apoptosis under $\mathrm{H} / \mathrm{R}$ conditions as shown by flow cytometry analysis as compared to the miR-138 mimic + H/R group (Figure $4 \mathrm{D}, p$ $<0.001$ ). Western blot results exhibited that miR138 mimic + ICAM-1 markedly reduced $\mathrm{Bcl}-2$ protein expression $(p<0.001)$ in $H / R$ cells as compared to the miR-138 mimic $+\mathrm{H} / \mathrm{R}$ group and increased the protein expression levels of cleaved caspase-3 $(p<0.05)$, cleaved caspase- 9 $(p<0.01)$, and $\operatorname{Bax}(p<0.001$, Figure $4 \mathrm{E})$.

\section{DISCUSSION}

The underlying mechanisms of cardiac I/R injury are not fully understood due to a variety of factors, including mitochondrial dysfunction, onset of cardiomyocyte apoptosis, and mitochondrial defects [16]. Understanding the complexity of pathological reperfusion injury and its underlying mechanisms might provide insights into developing promising therapeutic strategies targeting cardiac $\mathrm{I} / \mathrm{R}$ injury. In this study, a decreased expression of miR-138 was observed in both in vivo and in vitro. AgomiR-138 reduced myocardial infarction area, decreased ROS production and suppressed cell apoptosis in a rat model of cardiac I/R injury.

On the other hand, miR-138 mimics increased cell viability, enhanced ROS production and induced cell apoptosis in $\mathrm{H} / \mathrm{R}$-induced $\mathrm{H} 9 \mathrm{C} 2$ cells. Further analysis verified ICAM-1 as a target ofmiR-138. Besides, exogenous ICAM-1 abolished the protection of miR-138 in $\mathrm{H} 9 \mathrm{C} 2$ cells that induced by $H / R$. These data demonstrated that miR-138 expression might be involved in the $1 /$ R-induced injury of cardiomyocyte through ICAM-1. MiR-106b-5p, miR-424, and miR-99a play critical roles in cardiac I/R injury [17]. 


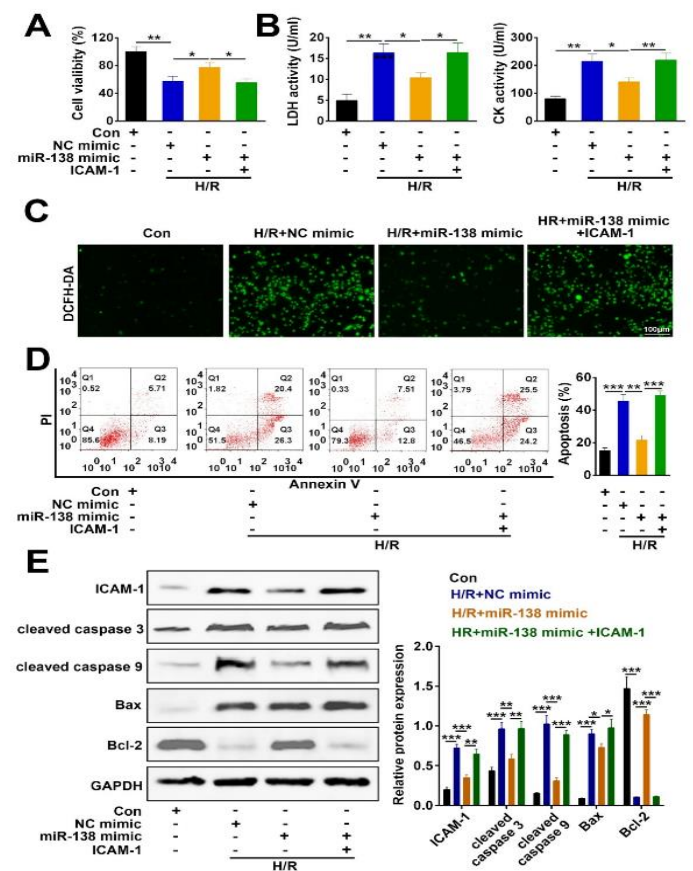

Figure 4: Exogenous ICAM-1 inhibited the protective effects of miR-138 mimics on H/R-induced H9C2 cells. (A) Cell viability was measured using MTT assay. (B) $\mathrm{LDH}$ and $\mathrm{CK}$ levels in $\mathrm{H} 9 \mathrm{C} 2$ cells were measured with ELISA. (C) ROS levels in H9C2 cells were measured by fluorometric analysis. (D) Cell apoptosis was evaluated by Annexin V-FITC/PI double staining. (E) Apoptosis-associated protein expression levels were evaluated by western blot; ${ }^{* *} p<0.01,{ }^{* * *} p<0.001$ vs. control group; ${ }^{\prime} p<0.05,{ }^{\#} p<0.01,{ }^{\# \#} p<0.01$ vs. H/R + NC-mimic group; ${ }^{*} p<0.05,{ }^{\&} \& p<0.01$, \&\&\& $p<0.001$ vs. $\mathrm{H} / \mathrm{R}+\mathrm{miR}-138$ mimic group

In particular, miR-138is reported to be a cardiacenriched miRNA, [18]. In the present experiments, a decreased expression ofmiR-138 was observed in both $\mathrm{l} / \mathrm{R}$ rats and $\mathrm{H} / \mathrm{R}$ cells.

Lactate dehydrogenase (LDH) and CK are important serum enzyme biomarkers of myocardial infarction and are released from damaged cells [19]. Energy produced by healthy mitochondria functions in the form of ATP, while damaged mitochondria result in ROS accumulation [20]. Reduction of damaged mitochondria protects against cell death and maintains normal mitochondrial function. Apoptosis exerts a critical effect on cardiac $\mathrm{I} / \mathrm{R}$ injury by activating apoptosis-associated proteins [21]. Results from our study indicated that, in the rat $\mathrm{I} / \mathrm{R}$ injury model, downregulation of miR-138 occurred together with an increased myocardial infarction area, accumulation of $\mathrm{LDH}$ and $\mathrm{CK}$ expression, elevated ROS levels, and apoptotic rates. Moreover, upon H/R stimulation, cell viability, $\mathrm{LDH}$ and $\mathrm{CK}$ expression, formation of ROS, and cell apoptosis showed similar trends to those of in vivo experiments, which demonstrated upregulated cleaved caspase-9, Bax and cleaved caspase-3activitiesand decreased $\mathrm{Bcl}-2$ activity. Importantly, miR-138 overexpression promoted these changes in cellular activity and ROS accumulation in I/R rats and partially attenuated these events in $\mathrm{H} 9 \mathrm{C} 2$ cells upon $\mathrm{H} / \mathrm{R}$ stimulation.

The biological functions of most miRNAs are exerted through binding to their target molecules, but it is unclear whether miR-138 affects I/Rinduced injury [22]. Therefore, bioinformatics website (www.microrna.org/were) was used to screen the potential targets of miR-138, and its downstream target (ICAM-1) may participate in I/R-induced injury. ICAM-1 is widely expressed in fibroblasts, macrophages, lymphocytes, and vascular endothelial cells, among other cell types [10]. For example, ICAM-1 is expressed in several human colonic epithelial cell lines and is upregulated in these cells upon invasive bacterial infection [23].

The present study showed that ICAM-1 expression was improved in $\mathrm{I} / \mathrm{R}$ injury-induced rats. In addition, ICAM-1 was identified as a target of miR-138, which was evaluated by dual luciferase assays. MiR-138 can also negatively regulate $I C A M-1$ expression. Functional analysis further indicated that exogenous ICAM-1 significantly decreased $\mathrm{H} 9 \mathrm{C} 2$ cell survival rates under H/R conditions and increased LDH and CK activities, ROS levels and induced cell apoptosis, as indicated by increased cleaved caspase-3, Bcl-2, cleaved caspase- 9 and decreased Bax expression.

\section{CONCLUSION}

This study demonstrates that miR-138 mediates cardioprotection against myocardial $\mathrm{I} / \mathrm{R}$ injury by targeting ICAM-1. It also throws some light on miR-138/ICAM-1 axis as a new therapeutic target for heart disease.

\section{DECLARATIONS}

\section{Conflict of interest}

No conflict of interest is associated with this work.

\section{Contribution of authors}

We declare that this work was done by the authors named in this article and all liabilities pertaining to claims relating to the content of this article will be borne by the authors. 


\section{Open Access}

This is an Open Access article that uses a funding model which does not charge readers or their institutions for access and distributed under the terms of the Creative Commons Attribution License (http://creativecommons.org/licenses/by/ 4.0) and the Budapest Open Access Initiative (http://www.budapestopenaccessinitiative.org/rea d), which permit unrestricted use, distribution, and reproduction in any medium, provided the original work is properly credited.

\section{REFERENCES}

1. Chow EJ, Chen $Y$, Hudson MM, Feijen EAM, Kremer LC, Border WL, Green DM, Meacham LR, Mulrooney DA, Ness KK. Prediction of ischemic heart disease and stroke in survivors of childhood cancer. J Clin Oncol 2017; 36(1): 44-52.

2. Dwyer DS, Vegt FPV, Bartels J, Brown GB. miR-30 Regulates Mitochondrial Fission through Targeting p53 and the Dynamin-Related Protein-1 Pathway. Plos Genet 2010; 6(1):e1000795-e1000808.

3. Ham O, Lee SY, Chang YL, Park JH, Lee J, Seo HH, Cha MJ, Choi E, Kim S, Hwang KC. let-7b suppresses apoptosis and autophagy of human mesenchymal stem cells transplanted into ischemia/reperfusion injured heart 7by targeting caspase-3. Curr Stem Cell Rest 2015; 6(1): 1-11.

4. Friedman RC, Farh KCB, Bartel DP. Most mammalian mRNAs are conserved targets of microRNAs. Genome Res 2008; 19(1): 92-105.

5. Almeida MI, Rui MR, Calin GA. MicroRNA history: Discovery, recent applications, and next frontiers. Mutat Res 2011; 717(1):1-8.

6. Chai L, Zhang XZ, fang Ma H, Yuan F. MiR-498 suppresses proliferation and inflammation in fibroblastlike synoviocytes in rheumatoid arthritis via targeting JAK1. Trop J Pharm Res 2019; 18(10): 1596-9827.

7. Han $Q$, Zhang $H Y$, Zhong $B L$, Zhang $B$, Chen $H$. Antiapoptotic Effect of Recombinant HMGB1 A-box Protein via Regulation of microRNA-21 in Myocardial Ischemia-Reperfusion Injury Model in Rats. Dna Cell Biol 2016; 35(4): 192-202.

8. Tang XJ, Yang MH, Cao G, Lu JT, Luo J, Dai LJ, Huang KM, Zhang LI. Protective effect of microRNA-138 against cerebral ischemia/reperfusion injury in rats. Exp Ther Med 2016; 11(3):1045-1050.

9. Yu C, Wang M, Li Z, Xiao J, Peng F, Guo X, Deng Y, Jiang J, Sun C. MicroRNA-138-5p regulates pancreatic cancer cell growth through targeting FOXC1. Cell Oncol 2015; 38(3): 173-181.

10. Berin MC, Egan LJ, Miyamoto Y, Kagnoff MF. Role of EHEC 0157:H7 virulence factors in the activation of intestinal epithelial cell NF-kB and MAP kinase pathways and the upregulated expression of interleukin 8. Cell Microbiol 2010; 4(10): 635-648.

11. Rong $L R$, Jun $L$, Jiu Yu G, Fang $K$, Yun LJ, Si ZY, Li MQ, Jun SC, Truax AD, Feng G. MicroRNA-141 regulates the expression level of ICAM-1 on endothelium to decrease myocardial ischemia-reperfusion injury. Am J Physiol Heart Circ Physiol 2015; 309(8): 1303-1313.

12. Zimmermann M. Ethical guidelines for investigations of experimental pain in conscious animals. Pain 1983; 16(2): 109-110.

13. Zhang $X, D u Q$, Yang Y, Wang J, Dou S, Liu C, Duan J. The protective effect of Luteolin on myocardial ischemia/reperfusion (I/R) injury through TLR4/NFKB/NLRP3 inflammasome pathway. Biomed Pharmacother 2017; 91: 1042-1052.

14. Livak KJ, Schmittgen TD. Analysis of relative gene expression data using real-time quantitative $P C R$ and the 2- $\triangle C C T$ method. Methods 2001; 25(4): 402-408.

15. Jin $Y$, Chen Z, Liu $X$, Zhou $X$. Evaluating the microRNA targeting sites by luciferase reporter gene assay. Methods Mol Biol 2013; 936: 117-127.

16. Hao M, Zhu S, Hu L, Zhu H, Wu X, Li Q. Myocardial Ischemic Postconditioning Promotes Autophagy against Ischemia Reperfusion Injury via the Activation of the nNOS/AMPK/mTOR Pathway. Int J Mol Sci 2017; 18(3): 614-630.

17. Li P, Shen M, Feng G, Wu J, Zhang J, Teng F, Zhang $C$. An Antagomir to MicroRNA-106b-5p Ameliorates Cerebral Ischemia and Reperfusion Injury in Rats Via Inhibiting Apoptosis and Oxidative Stress. Mol Neurobiol 2016; 54(4): 1-21.

18. Khandal $H$, Parween $S$, Roy $R$, Meena MK, Chattopadhyay D. MicroRNA profiling provides insights into post-transcriptional regulation of gene expression in chickpea root apex under salinity and water deficiency. Sci Rep 2017; 7(1): 4632-4646.

19. Janota T. Biochemical markers in the diagnosis of myocardial infarction. Cor Et Vasa 2014; 56(4): e304e310.

20. Tang Y, Liu J, Long J. Phosphatase and tensin homologinduced putative kinase 1 and Parkin in diabetic heart: Role of mitophagy. J Diabetes Invest 2015; 6(3): 250255.

21. Nakka VP, Gusain A, Mehta SL, Raghubir R. Molecular Mechanisms of Apoptosis in Cerebral Ischemia: Multiple Neuroprotective Opportunities. Mol Neurobiol 2008; 37(1): 7-38.

22. Ebert M, Sharp P. Roles for MicroRNAs in Conferring Robustness to Biological Processes. Cell 2012; 149(3): 515-524.

23. Girardin SE, Boneca IG, Carneiro LAM, Antignac $A$, Jéhanno $M$, Viala J, Tedin $K$, Taha M-K, Labigne $A$, Zäthringer $U$. Nod1 detects a unique muropeptide from gram-negative bacterial peptidoglycan. Science 2003; 300(5625): 1584-1587. 